\title{
Conexões
}

Educação Física, Esporte e Saúde

DOI 10.20396/conex.v18i0.8659312

Artigo Original

\section{A Lógica Interna do squash e as aprendizagens do jogo}

\author{
Erick Lisboa de Mesquita ${ }^{1}$ \\ Rodrigo Wanderley de Sousa-Cruz ${ }^{1}$ \\ Silvester Franchi ${ }^{2}$ \\ Leys Eduardo dos Santos Soares ${ }^{3}$
}

\section{RESUMO}

Introdução: A pesquisa é oriunda de uma parceria entre grupos de pesquisa que investigam o jogo como linguagem subjetiva e que possui uma gramática singular de análise ancorada pela Praxiologia Motriz, criada por Pierre Parlebas. Objetivo: Analisar as possíveis aprendizagens da prática do squash a partir de sua lógica interna. Metodologia: Trata-se de uma análise praxiológica, com ênfase na lógica interna tendo em vista a descrição da essência desse jogo esportivo. A metodologia é de abordagem qualitativa, com caráter descritivo, embasada pela Praxiologia Motriz (PM). Resultados e discussão: De acordo com a PM, o squash pode ser classificado como um jogo sociomotriz com presença de adversário e ausência de companheiro (1x1) ou presença de companheiro e adversário $(2 \times 2)$ e ausência de instabilidade e incerteza quanto ao entorno físico. A partir dos resultados desta pesquisa evidenciamos que a PM oferece subsídios para um rol de possibilidades de aprendizagens na prática do squash. Considerações Finais: As aprendizagens geradas pelas interações entre jogadores, espaços e implementos favoreceram um maior conhecimento das ações motrizes desenvolvidas nas situações do squash, o que contribuiu em informações analíticas para alunos e professores que atuam com o esporte.

Palavras-chave: Esporte com raquete. Aprendizagem. Interação. Praxiologia Motriz.

\footnotetext{
${ }^{1}$ Instituto de Educação Superior da Paraíba.

2 Universidade do Oeste de Santa Catarina.

3 Universidade Federal da Paraíba.
}

\section{Correspondência:}

Silvester Franchi. Universidade do Oeste de Santa Catarina. R. Getúlio Vargas, 2125, Flor da Serra, CEP 89600-000, Joaçaba - SC, Email: silvesterfranchi@hotmail.com 


\section{The Internal Logic of squash and game learning}

\section{ABSTRACT}

Introduction: The research is the result of a partnership between research groups that investigate the game as a subjective language and that has a singular grammar of analysis anchored by Motor Praxeology, created by Pierre Parlebas. Objective: To analyze the possible learnings of the practice of squash from its internal logic. Methodology: This is a praxeological analysis, with an emphasis on internal logic in view of the description of the essence of this sports game. The methodology has a qualitative approach, with a descriptive character, based on Motor Praxeology (PM). Results and discussion: According to the PM, squash can be classified as a sociomotor game with the presence of an opponent and the absence of a partner (1x1) or the presence of a partner and opponent $(2 \times 2)$ and the absence of instability and uncertainty regarding the physical environment. From the results of this research, we show that the PM offers subsidies for a range of learning possibilities in the practice of squash. Final Considerations: The learning generated by the interactions between players, spaces, and implements favored a greater knowledge of the motor actions developed in squash situations, which contributed to analytical information for students and teachers who work with the sport.

Keywords: Racket sport. Learning. Interaction. Motor Praxeology.

\section{Lógica Interna del squash y los aprendizajes de juego}

\section{RESUMEN}

Introducción: La investigación proviene de una asociación entre grupos de investigación que investigan el juego como lenguaje subjetivo, poseedor de una gramática singular de análisis bajo los conceptos de la Praxiología Motriz, creada por Pierre Parlebas. Objetivo: Analizar los posibles aprendizajes de la práctica del squash a partir de su lógica interna. Metodología: El estudio es un análisis praxiológico con énfasis en la lógica interna teniendo en vista la descripción de la esencia de ese juego Deportivo. La metodología es de abordaje cualitativa, con carácter descriptivo sostenida por la Praxiología Motriz (PM). Resultados y discusión: De acuerdo con la PM, el squash está ubicado en la categoría de juego sociomotriz con presencia de adversario y ausencia de compañeros (1x1) o presencia de compañero y adversarios (2x2) y ausencia de inestabilidad e incertidumbre respecto al entorno físico. Desde los hallazgos de esta investigación evidenciamos que la PM ofrece subsidios para un rol de las posibilidades de aprendizajes en la práctica del squash. Consideraciones finales: Los aprendizajes generados por las interacciones entre jugadores, espacios y objetos favorecen hacia un más amplio conocimiento de las acciones motrices desarrolladas en las situaciones del squash, lo que contribuye para las informaciones analíticas de los alumnos y profesores que actúan con este deporte.

Palabras Clave: Deportes de raqueta. Aprendizaje. Interacción. Praxiología Motriz. 


\section{INTRODUÇÃO}

O squash é uma modalidade esportiva que começou a ser praticada na Inglaterra, mais exatamente na cidade de Londres no século XIX. A versão mais aceita foi de que os prisioneiros nos momentos livres rebatiam contra a parede para se exercitar. O objetivo principal do jogo é rebater a bola contra a parede frontal através do manuseio de uma raquete para assim atingir também contra a parede lateral e a parede dos fundos. Atualmente o jogo é praticado em uma quadra fechada (indoor), em que as paredes (quatro) podem ser de alvenaria (imóvel) ou de vidro (móvel). Com isso, cada praticante manuseia uma raquete, e com a mesma bola (preta e de borracha) rebatem em direção à parede frontal. É possível utilizar as laterais e o fundo para rebater bola. O intuito principal da modalidade é induzir que o oponente não consiga rebater ou rebata fora das demarcações (linhas) que ficam nas paredes, convertendo assim os pontos. É um jogo esportivo ${ }^{4}$ em que os atletas ocupam os mesmos espaços da quadra. Em não consonância, os jogadores podem estar sujeitos a algumas situações perigosas. Por exemplo, a raquete ou a bola atingir o adversário durante a partida.

O squash é uma modalidade que não requer tempo determinado de partida como em outros esportes, como por exemplo, o basquete e o futebol. É o sistema de pontuação que determina sua finalização, mas podemos ter uma média de tempo de jogo que depende de fatores como, quantidade de games, equilíbrio técnico e principalmente do nível técnico do participante. A contagem dos pontos é disputada através de uma melhor de três ou cinco games, em que cada game é jogado até 11 pontos. O jogador que atingir 11 pontos primeiro vence o game, a não ser que a contagem fique em 10 iguais, neste caso vence o game quem fizer 2 pontos de diferença. Os dois jogadores podem pontuar (pontos corridos). O sacador, se vencer uma jogada, marca um ponto e mantém o serviço, e o recebedor se vencer uma jogada, marca um ponto e se torna o sacador (COSTA; SILVA, 2013; REGRAS WSF-CBS-FSPB, 2010).

Nessa perspectiva, nos afastamos dos jogos culturalmente estabelecidos, amplamente praticados e possuidores de diversos estudos e contribuições científicas, e tentaremos neste trabalho apresentar uma contribuição praxiológica ao analisar o squash, um jogo esportivo ainda pouco praticado e estudado no âmbito da Educação Física. Durante o jogo de squash, diversas interações são geradoras de possíveis aprendizagens adquiridas pelos jogadores. Assim, a PM sendo aplicada ao estudo das ações do jogo de squash pode oferecer um conhecimento inédito e enriquecedor para os praticantes e não praticantes que querem conhecer o esporte.

\footnotetext{
${ }^{4}$ Situação motriz de enfrentamento codificado, denominado "jogo" ou "esporte" pelas as instâncias sociais. Cada jogo esportivo se define por um sistema de regras que determina sua lógica interna.
} 
A Praxiologia Motriz é a ciência da ação motriz, criada pelo o Prof. Pierre Parlebas, que vem tecendo esta disciplina desde a década de 1960. O conhecimento praxiológico preocupa-se em desvelar a gramática dos jogos e esportes ao reconhecer as consequências das ações motrizes pertinentes a cada prática. De acordo com Parlebas (2001), a ação motriz trata-se da realização de condutas em uma situação real e objetiva de jogo. Ressalta-se que não é qualquer tipo de ação que pode ser considerada como ação motriz. Esse conceito abarca ações determinantes ao funcionamento do jogo, a exemplo dos passes no futebol e dos bloqueios no voleibol. Portanto, ações como limpar o rosto ou beber água durante o jogo não são consideradas ações motrizes, pois não determinam a situação motriz vivenciada.

Analisar as ações motrizes nos permite compreender as características da lógica interna de determinado jogo, isto é, as ações e obrigações impostas pelo estatuto do jogo que compreendem em sua prática as características internas do funcionamento de qualquer jogo ou esporte. Desse modo, compreender a lógica interna do squash, por exemplo, significa conhecer as características essenciais de seu funcionamento.

O squash em sua modalidade $1 \times 1$ se apresenta como possuidor de uma lógica interna de contracomunicações motrizes que exige dos jogadores rápidas tomadas de decisões tendo que levar em consideração o espaço compartilhado da quadra, a localização do oponente e a velocidade e direção da bola. De acordo com Parlebas (2001), a contracomunicação é uma interação motriz de oposição, trata-se da realização de ações que tem como objetivo se opor, dificultar e impedir as ações de adversários. A contracomunicação motriz pode manifestarse de diferentes formas, seja impedindo a realização de determinada ação adversária ou agindo de modo a ludibriar os adversários na execução de fintas e marcações, por exemplo. Lavega (2008) ressalta que essas interações de oposição podem ser corporais, a exemplo dos esportes de luta, e podem ser também instrumentais, como ocorrem com os esportes de raquete.

Estas ações estão presentes em todos os jogos ou esportes que para serem praticados é preciso que jogadores ou equipes se enfrentam no mesmo espaço. Diferentemente da modalidade de squash $2 \times 2$, onde ocorrem também comunicações motrizes, isto é, ações de apoio e cooperação de participantes de uma mesma equipe, na modalidade $1 \times 1$ os participantes necessitam superar 0 adversário sem ajuda de companheiros, ao elaborar estratégias e antecipações para se sobressair nas situações.

Sendo assim, a prática do squash permite 0 desenvolvimento de aprendizagens que determinam a qualidade de uma partida. Nessa perspectiva esta pesquisa buscará responder a seguinte questão-problema: Quais as possíveis aprendizagens geradas nas interações de contracomunicação motriz (oposição) na prática do squash? A pesquisa tem como objetivo 
analisar como a praxiologia motriz pode auxiliar no desvelamento das possíveis aprendizagens desempenhadas pelos praticantes de squash nas situações motrizes de oposição em relação aos jogadores, espaços e objetos.

Ao investigarmos as aprendizagens do squash (1x1) a partir de sua lógica interna, buscamos evidenciar que a prática desse jogo determina "normas que o jogador interioriza e transmite a seu corpo quando joga. Esta lógica intrínseca canaliza de forma mais ou menos clandestina um autêntico código de comportamento, de utilização do corpo e de relações humanas" (PARLEBAS, 2001, p.305). Por outras palavras, podemos inferir que a prática do squash, ao favorecer o enfrentamento de situações de contracomunicação motriz, proporciona configurações de comportamento nas relações que se estabelecem no jogo, determinando assim diferentes modos de aprendizagem para a atuação no jogo e isso pode evidenciar consequências importantes para atletas e jogadores ao pensar o treinamento para o desempenho durante o jogo nas dimensões técnicas (habilidades), táticas (estratégias) e condutas (modo de agir).

\section{MÉTODO}

Este estudo é oriundo de uma parceria entre grupos de pesquisa da Universidade Federal da Paraíba (Laboratório de Estudos e Pesquisas em Pedagogia da Corporeidade - LEPEC - Brasil) e da Universidade Federal de Santa Maria (Grupo de Estudos Praxiológicos - GEP - Brasil) que vêm produzindo pesquisas sobre a praxiologia motriz e suas contribuições para análise dos jogos tradicionais e esportivos no campo da educação física (GOMES-DA-SILVA et al., 2017; GOMESDA-SILVA; SOUSA-CRUZ; ARRUDA, 2019; SOARES; GOMES-DA-SILVA; RIBAS, 2012; SOUSA-CRUZ et al., 2015; SOUSA-CRUZ et al., 2017; SOUSA-CRUZ; GOMES-DA-SILVA; RIBAS, 2015).

Trata-se de uma pesquisa descritiva e de tratamento qualitativo dos dados. Foram observadas sessões de treinos do jogo de squash, em um centro de treinamento especializado, denominado Squash Bessa, localizado no bairro do Bessa na cidade de João Pessoa-PB. Este centro já sediou o Campeonato Brasileiro (2015) e o Top Class de João Pessoa, nível regional, entre os anos 2009 e 2019 e é reconhecido entre os atletas pela qualidade do espaço e pela formação de novos atletas.

Neste centro de treinamento foram observadas 30 sessões de treino de squash com alunos que já praticavam o esporte. As aulas eram ministradas por um dos pesquisadores do estudo - Profissional de Educação Física - atleta de squash, 9 vezes e atual campeão paraibano e campeão brasileiro categoria máster $25 \mathrm{~A}$ (2011). O mesmo é sócio proprietário do centro e ministra aulas de squash há 15 anos. Por conseguinte, somamos o seu conhecimento técnico do squash com o 
olhar da Praxiologia Motriz dos demais investigadores.

Parlebas (2001) elaborou uma classificação para aplicar a quaisquer práticas motrizes partindo de uma concepção no que o participante interage globalmente com o entorno físico e com outros possíveis protagonistas. São três critérios de interação que compõe o sistema de classificação da práticas motrizes (CAI): o primeiro, leva em consideração a presença ou ausência de companheiros (C); o segundo, diz respeito à presença ou ausência de adversários (A); e o terceiro, considera o entorno físico em sua presença ou ausência de incerteza (I). No quadro 1 está descrito o sistema de classificação, no qual as letras sublinhadas correspondem à ausência de interação.

Quadro 1 - Classificação das práticas motrizes (CAI)

\begin{tabular}{|c|c|}
\hline Classificação & Tipo de Prática Motriz \\
\hline$\underline{\text { CAI }}$ & $\begin{array}{l}\text { 1- Psicomotriz em ambiente estável: Práticas em solitário, sem } \\
\text { interações com companheiro e/ou adversários, realizadas em meio } \\
\text { estável. Por exemplo: Ginástica Rítmica Individual, Patinação } \\
\text { individual, Barras paralelas. }\end{array}$ \\
\hline$\underline{\text { CAI }}$ & $\begin{array}{l}\text { 2- Psicomotriz em ambiente instável: Práticas em solitário realizadas } \\
\text { em ambiente instável. Estamos diante das atividades psicomotrizes } \\
\text { realizadas na natureza. Por exemplo: Esqui, Canoagem e Surf. }\end{array}$ \\
\hline$\underline{C} A \underline{I}$ & $\begin{array}{l}\text { 3- Sociomotriz de oposição em ambiente estável: Práticas de interação } \\
\text { com adversários, realizadas num meio estável. Não há interações com } \\
\text { companheiros, por exemplo: Karatê, Taekwondo, Tênis, squash (1x1). }\end{array}$ \\
\hline$\underline{C} A I$ & $\begin{array}{l}\text { 4- Sociomotriz de oposição em ambiente instável: Práticas de } \\
\text { interação com adversários, realizadas em um ambiente instável. Por } \\
\text { exemplo: Regata de vela individual e Triathlon. }\end{array}$ \\
\hline CAI & $\begin{array}{l}\text { 5-Sociomotriz de cooperação em meio estável: Práticas de interação } \\
\text { com companheiros, realizadas em um meio estável. Por exemplo: } \\
\text { patinação em duplas e dança clássica. }\end{array}$ \\
\hline CÁI & $\begin{array}{l}\text { 6-Sociomotriz de cooperação em meio instável: Práticas de interação } \\
\text { com companheiros, realizadas em ambiente instável. São exemplos: } \\
\text { Alpinismo em equipe, Vela com tripulação. }\end{array}$ \\
\hline CAI & $\begin{array}{l}\text { 7-Sociomotriz de cooperação e oposição em meio estável: Práticas de } \\
\text { interação com companheiros e adversários, realizadas em ambiente } \\
\text { estável. São exemplos: Futebol, Handebol e Squash }(2 \times 2) \text {. }\end{array}$ \\
\hline CAI & $\begin{array}{l}\text { 8- Sociomotriz de cooperação e oposição em meio instável: São } \\
\text { práticas com presença de interação entre companheiros e adversários, } \\
\text { realizadas em ambiente instável. São exemplos: os jogos praticados } \\
\text { na natureza. }\end{array}$ \\
\hline
\end{tabular}

Fonte: Adaptado de Parlebas (2001).

A partir do Quadro 1 compreendemos que a classificação do squash depende da modalidade que está em análise, havendo, portanto, duas possibilidades de classificação. O squash $1 \times 1$ é uma prática sociomotriz de oposição. Porém, quando o squash é praticado na modalidade $2 \times 2$, sua classificação é sociomotriz de cooperação e oposição simultâneas. Nesta pesquisa 
analisaremos 0 squash em sua modalidade $1 \times 1$, com a finalidade de investigar as possíveis aprendizagens decorrentes de sua prática. A partir da teoria praxiológica, analisaremos os componentes da lógica interna dos jogos e esportes conforme apresentados por Lagardera e Lavega (2008), exceto o item tempo de jogo. Justifica-se esta escolha pela razão de que é a análise das interações dos Jogadores, Espaço e Objetos que nos fornecem informações mais objetivas no que concerne às aprendizagens do jogo e suas possíveis contribuições para a Educação Física:

a) "Jogadores" - Trata-se das interações motrizes realizadas entre os participantes do jogo. Corresponde a análise das aprendizagens geradas a partir das interações de contracomunicação motriz.

b) "Espaço Pertinente" - Esta categoria nos permite analisar quais as relações que os jogadores estabelecem com o espaço de jogo, como utilizam as possibilidades do espaço no enfrentamento das situações motrizes;

c) "Implementos" - Analisamos nesta categoria as relações que os jogadores estabelecem com os objetos do jogo. Observamos como os jogadores interagem com os objetos para atuar nas jogadas.

\section{Resultados e Discussão}

O esporte squash analisado no presente estudo (1x1) deve ser compreendido como um sistema dinâmico de situações motrizes. Como em qualquer jogo ou esporte, se nos determos apenas em analisar a lógica interna de jogo, ou seja, identificar as relações/interações possíveis a partir de seu sistema de regras e possibilidades de ação através da intuição de como se dá a atuação dos indivíduos que estão dispostos a jogar, não conseguiremos visualizar as múltiplas possibilidades do atuar humano nas mais variadas manifestações, seja entre os jogadores, no espaço e com os materiais de jogo.

Desta forma, apresentamos a seguir algumas análises sobre o squash que pudemos evidenciar tanto em suas características fundamentais relacionadas à lógica interna em suas regras, assim como compreender as diferentes formas de os indivíduos se relacionarem no jogo a partir da observação da atuação de jogadores.

\section{SITUAÇÕES MOTRIZES DE CONTRACOMUNICAÇÃO - JOGADORES}

As movimentações durante o jogo de squash são ações motrizes muito intensas, isto é, o jogo exige uma capacidade de reação constante a cada rebatida, e as ações realizadas pelos jogadores tem como finalidade dificultar o 
máximo possível a rebatida do oponente. A relação de contracomunicação começa a partir do momento que um jogador executa o saque soltando a bola no ar para rebater sem que ela caia no chão e chegue ao lado de seu adversário. Logo que o sacador realiza sua ação, busca posicionar-se na região central da quadra, desta forma o jogo começa a se estabelecer a partir de uma disputa entre buscar o espaço central da quadra e fazer com que o adversário se desloque do centro.

Buscando cumprir esta estratégia para o início do jogo, a partir das observações realizadas, o jogador sacador procura agir com a maior eficiência possível colocando a bola alta, no canto da parede lateral e no fundo da quadra visando dificultar a ação do recebedor, e este caso consiga rebater, geralmente busca responder a bola no canto da parede e o mais longe possível do jogador que sacou obrigando-o a deslocar-se da região central para que o jogador que recebeu no início do saque possa ficar melhor posicionado na quadra.

Essas são ações de contracomunicações motrizes frequentemente utilizadas no jogo de squash, jogar a bola alta na parede lateral e no fundo da quadra, dificulta a ação do oponente por exigir um deslocamento maior e maior habilidade para se posicionar e rebater a bola também de modo a colocar o oponente em situação de desafio. Em uma primeira mirada, a situação de início de jogada descrita, leva o leitor a crer que sempre ocorre da mesma maneira, porém devemos salientar que por se tratar de uma situação sociomotriz de oposição, ambos os jogadores, como salienta Parlebas (2001), são centros originais de decisões e ações imprevista para os demais.

O squash é um esporte que exige dos participantes rápidas adaptações das condutas motrizes às situações de jogo considerando os indícios reconhecidos nas mais variadas situações motrizes (PARLEBAS, 2001), os indícios são capazes de representar, revelar, um acontecimento ou possibilidade de atuação que não se pode perceber de maneira imediata. No jogo de squash isto se traduz nos comportamentos observáveis da posição do jogador em quadra, posição em relação à bola, trajetória da raquete ao realizar a rebatida.

Quando estamos realizando análises acerca das interpretação das informações observáveis no comportamento motor dos jogadores, devemos ainda considerar que os indícios apresentados pelos jogadores podem ser uma indução a uma conduta que não será realizada, ou seja, o jogador, como Parlebas (2001) afirma, gera um contraindício para enganar o adversário. A incerteza gerada perpassa pelas decisões motrizes do contrário que são subjetivas e cambiantes conforme o rol de possibilidades de ação que o indivíduo pode realizar. Vamos perceber que maior evidência mais adiante ao tratarmos de decisões motrizes para a realização de drop e/ou lob.

A característica do squash ao se definir como uma modalidade de decisões 
motrizes e movimentos corporais rápidos, principalmente dadas pela ação motriz de rebater, que de forma geral, define todas as ações motrizes perceptíveis no jogo. O rebater, sendo central em um jogo ou esporte, nos "fala" muito de como se dará a dinâmica de jogo, pois o justo tempo de posse de bola é o momento que ocorre a rebatida, desta forma o jogador é obrigado a antecipar-se em sua tomada de decisão para logo atuar com suas ações motrizes.

Ao observarmos a troca de rebatidas entre os jogadores é possível perceber que os jogadores adquirem maior êxito quando conseguem observar como é realizada a rebatida do adversário, qual seu posicionamento e direção tomada pela bola. Porém, em muitos momentos é difícil realizar essa análise e tentar uma antecipação devido a constante movimentação na quadra. Assim, percebemos que a tomada de decisão ocorre muitas vezes após a bola bater na parede o que exige uma capacidade de reação e adaptação à situação. Esta reação rápida que nomeamos aqui, é compreendida por Parlebas (2001) como a conduta motriz que o indivíduo/jogador utilizou para dar seguimento ao jogo, no entanto colocar em prática sua conduta motriz de maneira eficaz somente é possível após haver a percepção das ações do adversário, os indícios do que será realizado, assim culminando em pré-ações baseadas em antecipações motrizes.

Na prática do squash, essa questão de esperar o oponente rebater é um dos princípios básicos do jogo, porque quando o jogador reage antes ao fazer algum movimento, ele indica qual é sua intenção durante a disputa do ponto, e um jogador de squash experiente que vai rebater a bola, com certeza perceberá esse movimento antes da hora e vai tirar proveito da situação. O procedimento adequado é esperar o adversário rebater a bola para depois poder reagir a fim de não demonstrar através de seus gestos e movimentos o que se pretende fazer.

Os movimentos utilizados nesse jogo necessitam ser flexíveis, isto é, é necessário ter uma capacidade de adaptação à situação emergente, a utilização de movimentos isolados torna-se inviável devido a variabilidade de direcionamento que a bola pode tomar, exigindo uma rápida resposta. Isso se torna cada vez mais evidente quando os níveis dos praticantes ficam mais elevados. As execuções das rebatidas durante a disputa do ponto ficam mais potentes e com maior precisão imprimindo uma grande capacidade de deslocamento de seu oponente. Este, por sua vez, deve ter agilidade e explosão para poder alcançar a bola o mais rápido possível e ao mesmo tempo tomar identificar a melhor decisão motriz a ser executada levando em consideração ao que afirma Parlebas (2001) sobre a antecipação motriz, em que o jogador busca antecipar-se frente a um jogador que também se antecipa.

A tomada de decisão na escolha da ação motriz que se pretende utilizar no jogo, vai depender da situação que ocorre no momento da partida, pois alguns indícios devem-se levar em consideração, como, por exemplo, perceber a posição da raquete do adversário, seu posicionamento, as deficiência do 
adversário em determinada situação procurando explorá-la, assim realizando variações como realizar uma deixada (drop) ou levantar a bola (lob) para ganhar tempo na disputa do ponto.

O drop é fundamento considerado de ataque, isto é, uma jogada para definir o ponto durante uma partida de squash, pois é utilizada, principalmente, para o adversário que fica no fundo da quadra não conseguir chegar. É muito comum no squash de alto nível, os jogadores trocarem bastante bola até o momento em que um dos jogadores percebe que seu adversário cometeu o erro de devolver a bola fácil e no meio da quadra. Esse jogador, que recebe com facilidade a jogada do adversário, pode utilizar o drop a fim de tirar proveito da situação de desvantagem de seu oponente por estar mal posicionado, colocando a bola bem fraca e perto da parede.

Gomes-da-Silva, Sousa-Cruz e Arruda (2019) sobre a lógica interna de uma final de badminton observaram a utilização do drop. A atleta visualizou o espaço livre no canto esquerdo da quadra da adversária e, sabendo que a mesma estava bem perto da linha de fundo, executou uma batida em que simulou ser forte, mas apenas "empurrou" a peteca para que a mesma caísse mais próxima da rede da quadra adversária. Contudo, ela é uma jogada muita arriscada e com grande risco de erro se não estiver treinada, porque exige muita precisão do rebatedor na hora da execução. Portanto, o drop, sendo bem treinado e utilizado no momento certo, é uma jogada que define, em diversas situações, quando se ganha os pontos.

O Lob é fundamento de defesa do squash muito utilizado pelo jogador em momentos de dificuldades na disputa do ponto. Ele pode ser executado quando um jogador está sendo pressionado por seu adversário que está melhor posicionado e controlando as ações do jogo através de mais interceptações e se deslocando menos na quadra. Por exemplo, após o jogador colocar um drop, se o opositor chegar na jogada, uma ótima opção para esse tipo de situação é o lob, porquanto este está em uma situação difícil e precisa ganhar tempo para poder se recuperar na disputa do ponto, e o lob sendo executado corretamente (muita altura e pouca força para alcançar o fundo da quadra) pode oferecer isso. É importante citar que se consegue fazer pontos através de uma boa execução dessa ação motriz em caso de o jogador não interceptar a bola no alto, com isso a bola perde força e fica junto à parede do fundo da quadra. 


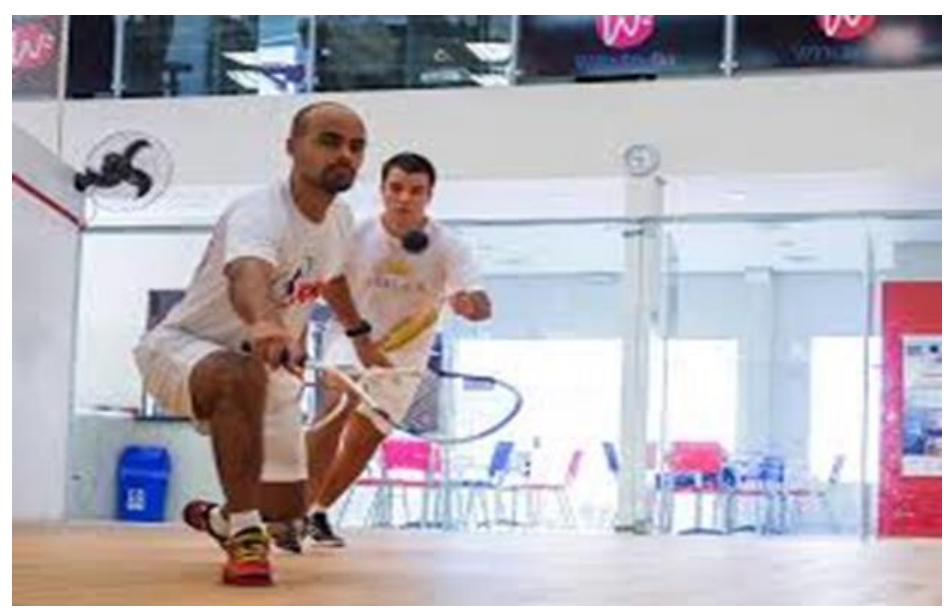

Figura 1 - O jogador deixando a bola (drop) para o oponente que está atrás dele alcançá-la. Fonte: Arquivo pessoal de Rodrigo Wanderley de Sousa-Cruz.

As interações de contracomunicação realizadas no squash exigem que o participante aprenda a reagir rapidamente, observando, como nos diz Lagardera e Lavega (2003) que para criar uma situação ótima de jogo varia de acordo com a capacidade de o jogador ler o outro, se fixar na posição de apoio dos pés, dos segmentos corporais, sua aceleração, a ocupação do espaço e sua localização e deslocamento sendo assim capaz de criar uma situação de jogo difícil para o oponente. Soares, Gomes-da-Silva e Ribas (2012) caracterizam estas ações aproximando com os conhecimentos praxiológicos do badminton como indução corporal, que consiste nas formas que o jogador utiliza seu corpo em movimento com o intuito de que seu adversário cometa erros.

Ao observamos os jogos é possível perceber o esforço dos participantes para aprender a criar situações difíceis, este aprendizado constante se dá a partir de estruturas globais dentro de um jogo, não de fragmentos (LAGARDERA; LAVEGA, 2003), assim podemos compreender que a realização de uma ação sempre é distinta de outra, ocasionando sempre novas fontes de incerteza e necessidade constante de leitura e tomadas de decisões a serem realizadas. Essas situações de dificuldades acontecem em vários momentos durante a disputa do ponto, uma situação comum é quando um jogador não consegue colocar (rebater) a bola nos cantos das paredes e a bola fica localizada nas proximidades do meio da quadra, pois o oponente, dependendo da qualidade técnica dele, vai ter o controle da partida que acontece da seguinte forma:

- Com mais utilização do fundamento voleio e interceptação de jogadas pelo jogador, o seu adversário é sufocado com menos tempo para respirar e pensar, consequentemente, vai cansar mais.

- Pôr a bola estar aberta, que é estar distante da parede, o jogador terá menos dificuldades em receber a bola rebatida por seu oponente.

- Em detrimento de seu adversário, por estar bem posicionado e recebendo 
a jogada com facilidade, ele vai correr e se esforçar muito menos para rebater o golpe exercido pelo o seu oponente, assim terá menos desgaste físico e psicológico.

\section{SITUAÇõES MOTRIZES DE CONTRACOMUNICAÇÃO - ESPAÇOS}

Quando o jogador inicia a disputa do ponto através do saque, automaticamente posiciona-se no meio da quadra, dependendo da resposta de seu adversário, ele vai ter que fazer um deslocamento rápido e distante. É importante que a movimentação dos jogadores de squash deva ser de uma forma que gaste o mínimo de energia possível na quadra, como por exemplo; procurar dar passadas largas em direção a bola e em menor número no momento que vai rebater, bem como, manter o equilíbrio e a postura adequada do corpo durante a movimentação.

Sobre essa relação de contracomunicação com o espaço de jogo devemos recorrer à Parlebas (2001) no tocante à distância de enfrentamento motor que significa uma distância codificada que separa os adversários de um jogo esportivo no instante do seu enfrentamento direto. Esta regulamentação da contracomunicação motriz é um elemento importante da lógica interna de cada jogo. O squash, apesar de ser um jogo esportivo de raquetes como o badminton, tênis e tênis de mesa não utiliza redes de separação dos jogadores. Ou seja, as interações ocorrem em um espaço próximo médio, haja vista que não possui muita proximidade como em outros esportes, tais como o basquete, futsal, handebol, por exemplo.

Tratando-se de modalidades com interação entre adversários, González (2017) explica que não é suficiente realizar de forma adequada os gestos técnicos demandados pelo o jogo esportivo, também é imprescindível escolher/decidir (individualmente - squash $1 \times 1$ ou individualmente e coletivamente - squash $2 \times 2$ ) o que fazer diante da situação criada pela dinâmica da prova ou jogo. O squash compõe a classe dos esportes alternado direto, pois a bola deve ser rebatida apenas a partir de um golpe.

Deste modo, o deslocamento dos jogadores deve ser de maneira eficiente, ou seja, é muito importante que seja com a menor quantidade de passadas possível, aliada à velocidade e à coordenação motora vai proporcionar um melhor desempenho dos praticantes durante a disputa. Portanto, a ação motriz de rebater com o objetivo de colocar a bola nos cantos das paredes e a movimentação adequada é - em muitas situações de jogo - a maneira mais eficaz de impor sua estratégia de jogo ao adversário, assim a contracomunicação motriz é o elemento definidor das situações de jogo.

A ação motriz rebater é a principal ação no jogo do squash. É a ação usada para escolhas e decisões constantes e vai além das capacidades físicas ou 
habilidades motoras. Compreendemos que "a técnica no squash, como em qualquer modalidade esportiva, é fundamental para sua aprendizagem. Primeiro, se aprendem todos os componentes técnicos para depois aprender como e quando utilizá-los (COSTA E SILVA, 2013, p. 3). Como nos preocupamos com a aprendizagem do jogo squash em uma perspectiva mais ampla, compreendemos pela ótica da lógica interna a partir de uma decisão motriz.

Segundo Parlebas (2001), as decisões motrizes implicam uma dimensão cognitiva determinante, como na valorização dos intervalos, velocidades e distâncias (nas situações motrizes de defesa e ataque no squash); na evolução das durações, acelerações e desacelarações (nas situações motrizes de táticas no squash); estimação dos encontros, convergências e ultrapassagens (nas situações motrizes de condutas motrizes); decodificações dos estímulos na condição de indícios que adquirem significados em um sistema de signos (nas situações motrizes de leitura do adversário, dos espaços e do objeto durante o jogo). Por exemplo, o gesto com as mãos pode indicar vários significados. Tanto no badminton (GOMESDA-SILVA; SOUSA-CRUZ; ARRUDA, 2019) como no squash pode ser um modo de disfarce para uma observação do melhor lugar do espaço e a escolha de uma rebatida (decisão) mais confiável para executar com base na posição do adversário.

No squash há uma constante disputa entre os adversários para devolver a bola em dificuldade. Esta disputa se dá concomitantemente ao objetivo de cada jogador de posicionar-se no $\mathrm{T}$ (posição do corpo sempre de frente a parede frontal), por mais tempo, assim, necessita se deslocar menos, aumentando muito as chances de êxito, desta forma obtém vantagem de impor sua tática de jogo frente ao adversário. Sobre esse espaço "T", que se localiza no centro da quadra, Costa e Silva (2013) nos alerta que não é um aspecto fácil de ser aprendido face a muitos outros itens estarem envolvidos para os jogadores durante o jogo. Acrescentam que o posicionamento do corpo na hora de rebater a bola deve: "do lado direito, deve-se virar de frente para a parede lateral, colocar a perna esquerda à frente do corpo, mantendo sempre o ombro esquerdo apontando para a parede frontal, e o direito, para a parede dos fundos. Do lado esquerdo, ocorre o inverso" (COSTA E SILVA, 2013, p.3).

Adentrando a outros aspectos do espaço, as paredes da quadra de squash são muito importantes para o jogo, pois tem a função de receber os golpes que os jogadores utilizam para conseguir o ponto. Ao mencionarmos as paredes como influência direta ao jogo devemos levar em consideração a criação de ângulos que estas proporcionam. Quando há rebatidas utilizando as laterais da quadra haverão os ângulos de entrada e saída da bola que deverão ser calculados rapidamente para que o jogador que prosseguirá com a jogada realize uma leitura adequada e se posicione corretamente.

As linhas das paredes e do chão são fundamentais para demarcar a área que pode ou não ser rebatida com a bola. Nas paredes, tem a linha superior que cerca a 
quadra inteira e a linha inferior (chamada de lata) apenas na parede frontal como área de jogo. As linhas intermediárias ficam localizados na parede frontal e chão com a função de delimitar o saque, pois a bola deve atingir acima da linha média da parede e ultrapassar a do chão e na demarcação contrária.

Diferentemente da maioria dos outros esportes de raquetes (tênis, badminton), o squash é um esporte que quando a bola atinge ou toca na linha é considerada inválida a jogada. Em cada lado da quadra tem um quadrado menor que tem como finalidade servir como a área em que o jogador vai executar o saque, pelo menos um pé (ou os dois pés) tem que estar dentro desse quadrado para que o saque seja considerado válido.

Um exemplo das relações estabelecidas dos jogadores no espaço foi observado após um jogador rebater a bola após o saque, ele devia voltar-se para o meio da quadra o mais rápido possível para estar pronto para o ponto seguinte e não atrapalhar seu adversário (passível de penalidade), isso serve para o outro jogador também que vai fazer a jogada seguinte.

A importância de rebater a bola longe de seu adversário está além da tática de jogo, pois contribui para a questão de segurança dos praticantes para que a raquete ou a bola não atinja o adversário, pois a bola estando distante, o jogador vai ter espaço para devolver a bola e executar o movimento sem colocar em risco a integridade física do oponente. Essa é uma característica importante do squash, exige a movimentação em um espaço compartilhado, porém, cada jogador tem responsabilidade sobre o seu adversário, pois é preciso jogar sem prejudicá-lo na movimentação no espaço.

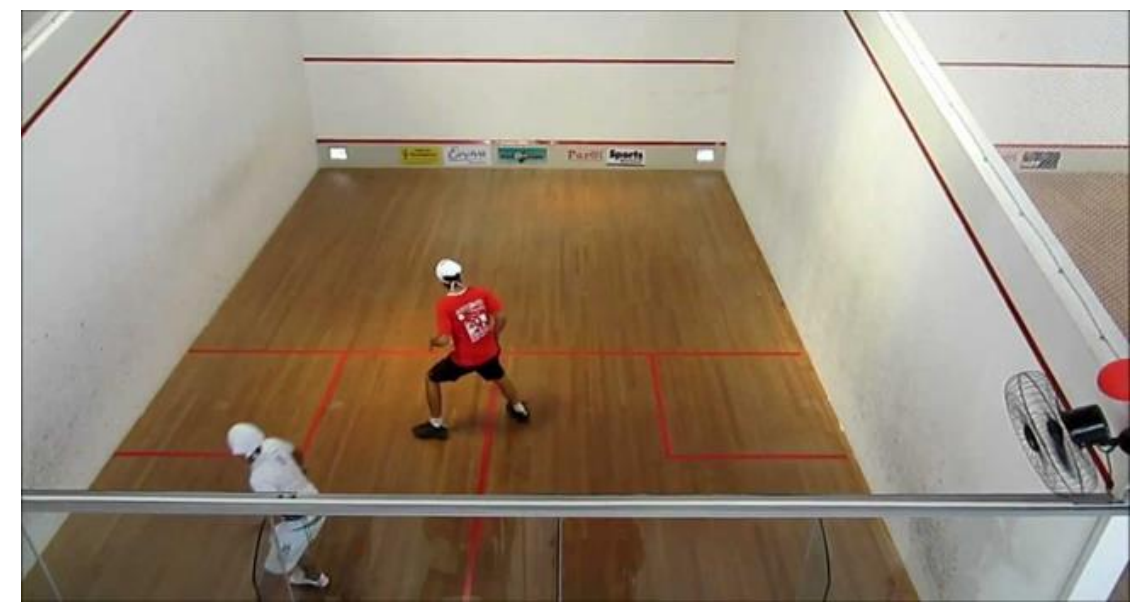

Figura 2 - O jogador (camisa vermelha) leva vantagem sobre o jogador (camisa branca) porque este não conseguiu tirar aquele do meio da quadra. Fonte: Arquivo pessoal de Rodrigo Wanderley de Sousa-Cruz.

Parlebas (2001) chama atenção para algo peculiar para análise desse jogo esportivo: a questão do duelo - situação de enfrentamento entre os adversários cujos interesses estão em lados opostos. "Em cada situação de duelo, se pode 
identificar uma interação oposta bem marcada: a contracomunicação motriz. Seus canais são vetores privilegiados da rede de comunicação motriz" (IDEM, p. 167). O squash está dentro de um duelo que Parlebas (2001) chama de simétrico. Isso se dá quando os protagonistas se encontram em condições idênticas e gozam do mesmo estatuto sociomotor do jogo em questão. Além disso, usam o mesmo espaço correspondente, mesmo número de jogadores e instrumentos.

Uma situação que acontece com frequência é quando existe o contato entre os jogadores no momento de disputa do ponto, por exemplo, o jogador ao colocar uma bola baixa (drop) para seu adversário tentar rebater a bola e por algum motivo técnico ou físico ocorre a interferência daquele que rebateu, é importante que ele saia o mais depressa possível daquele espaço porque se não o sair ou demorar muito, acaba atrapalhando seu oponente.

A movimentação no espaço compartilhado exige que cada atleta aprenda a se movimentar levando em consideração a presença do outro. Assim o squash se apresenta como uma modalidade que desenvolve nos jogadores noções espaçotemporais das quais os jogadores necessitam aprender para que consigam jogar sem sofrer penalidades.

\section{SITUAÇõES MOTRIZES DE CONTRACOMUNICAÇÃO - IMPLEMENTOS}

A relação do praticante de squash com os objetos inicia-se através do manuseio da raquete, uma das partes mais importantes no aprendizado da modalidade é segurar a raquete da maneira correta (empunhadura, posição de espera e posições para rebatida), garantindo segurá-la de forma correta e firme, principalmente no momento do contato com a bola para que a rebatida seja executada na direção, altura e força desejada. Corroboramos com Costa e Silva (2013) em estudo sobre a metodologia do ensino do squash. Para os autores é relevante que os jogadores mantenham um contato visual com a bola, uma preparação correta com a raquete para os golpes e um bom entendimento do jogo.

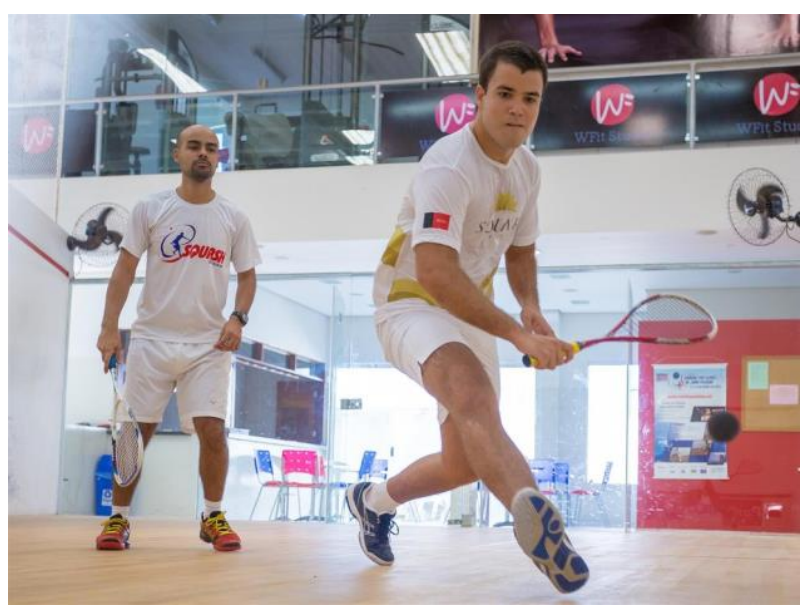

Figura 3 - Empunhadura e posicionamento em relação à bola e raquete. Fonte: Arquivo pessoal de Rodrigo Wanderley de Sousa-Cruz. 
Por isso que entender os movimentos de contracomunicação utilizados durante o jogo se torna imprescindível para tomada de decisões dos jogadores em relação à raquete e à bola. Assim eleva-se o nível técnico-tático do jogo e favorece o êxito de quem fizer a leitura dos gestos e movimentos do adversário. Isso suscita que os jogadores interpretem essas informações gestuais e táticas de si mesmo e dos outros para um raciocínio prévio nas tomadas de decisão e na sequência das ações durante os jogos (GOMES-DA-SILVA; SOUSA-CRUZ; ARRUDA, 2019; SOUSA-CRUZ; GOMES-DA-SILVA; RIBAS, 2015).

Em comparação com outros esportes com raquetes, como por exemplo: o tênis que tem variedades de empunhaduras na hora do golpe, o squash tem uma empunhadura única que vai ser utilizada em todos os fundamentos. Uma dica importante é que normalmente a raquete é segurada como se estivesse cumprimentando uma pessoa (aperto de mão) para que a cabeça da raquete fique ligeiramente inclinada para cima, isso faz com que na hora do acerto a bola adquira uma trajetória correta e dentro da área de jogo.

Através da interação com a raquete, ocorre a relação com a bola que é fundamental para que o praticante de squash aprenda a ter percepção de tempo e de espaço no momento do alcance na bola. Em uma situação observada, foi possível perceber que quando um jogador começa a disputa do ponto através do saque e o adversário responde de volta a jogada, a partir daí o sacador começa a perceber a velocidade com que a bola está. Por isso é adequado que sua movimentação seja proporcional a essa velocidade para que assim chegue no tempo certo. Essa movimentação do corpo no tempo da bola influencia diretamente no espaço do praticante de squash em relação a ela, porque um jogador que percebe o tempo correto, vai dar o espaço adequado (percepção espacial) para conseguir atingir a bola de maneira eficiente.

Quando isso não ocorre, o praticante tem dificuldades técnicas para jogar o squash, por que a movimentação desproporcional leva a se deslocar de maneira desnecessária (deslocamento rápido), com isso podendo acontecer a aproximação do praticante demais da bola e causando o erro no contato raquetebola (furada). Pode ocorrer de maneira contrária que é a movimentação lenta em direção a bola por não ter velocidade ou atenção suficiente para chegar na bola.

Nesse sentido, levando em consideração os implementos, é possível perceber que na prática de squash é preciso desenvolver uma percepção espacial para movimentar-se de acordo com o tempo da bola. Essa falta de percepção espacial é muito comum em pessoas que estão começando na modalidade, nas primeiras aulas, alguns aprendizes têm dificuldades ou não acertam a bola com a raquete no lugar correto (cabeça da raquete). Por isso deve-se trabalhar os movimentos técnicos utilizados no squash, primeiro, com a bola estática para o iniciante assimilar os movimentos básicos e adquirir um pouco desta percepção de espaço para assim depois começar a rebater a bola em movimento, por 
exemplo, o professor coloca a bola parada no chão e o aluno começa a fazer os movimentos técnicos usando esta bola estática como referência. Depois, o professor coloca a bola para o iniciante em cruzada, alta e o mais lenta possível, em seguida, o aluno rebate a bola de volta. Esse procedimento é feito várias vezes durante a prática do squash a fim de que o aluno consiga, através das repetições, aperfeiçoar a técnica.

\section{CONSIDERAÇÕES FINAIS}

Nossas últimas reflexões sobre esse estudo, caminha na compreensão que através da Praxiologia Motriz é possível aprender mais sobre como funciona a lógica interna do squash. Como um jogo esportivo sociomotriz, analisamos o duelo de oposição (1x1), apesar da existência do modelo de cooperação-oposição (2x2). Nas situações de oposição ou de contracomunicação motriz a interação se realiza diante de um adversário que se opõe às suas ações motrizes. No caso do squash é instrumental (com raquete e bola).

Nessa lógica interna estão inseridas as relações entre os adversários (contracomunicação), com espaço, com objetos e o tempo de partida (excetuamos este item de análise como limitação da pesquisa) para que o participante entenda de uma maneira clara as regras e condutas que o jogo tem em particular, com isso aumenta-se a capacidade da leitura das jogadas de seu adversário, ou seja, ver de forma consciente o jogo para assim tomar as melhores decisões.

Esse entendimento do funcionamento da lógica interna do squash se torna importante para os seus praticantes no que concerne às vantagens em relação ao seu oponente na hora de escolher as ações motrizes adequadas para determinada situação motriz e executá-la de forma correta dentro do contexto do jogo. Podemos citar algumas vantagens do conhecimento praxiológico para o jogo esportivo squash:

Com relação ao adversário - perceber melhor as ações motrizes gestuais (com as mãos, olhares, pernas) e de deslocamentos táticos durante as rebatidas (acelerações, recuos, desacelerações); entender que o duelo $1 \times 1$ exige uma oposição constante e menos erros, haja vista que não tem a cooperação do companheiro no caso do duelo $2 \times 2$ para uma cobertura da jogada;

Com relação aos espaços - ocupar os espaços com mais interação; valorizar as paredes frontais, laterais e de fundo como partícipes do jogo para além do local de prática; usar o chão como aliado para dificultar a rebatida adversária, pois a força e velocidade empregada pode gerar mais de um quique, o que resulta no erro do oponente e ponto para si. 
Com relação aos objetos - manusear a raquete como membro imprescindível do jogo com suas possibilidades para rebater; variar os golpes com a raquete de acordo com a situação motriz gerada no jogo; criar uma relação de comunicação uníssona com a bola para que se obtenha êxito nas condutas motrizes em virtude da ação de contracomunicação do adversário.

Por conseguinte, o estudo identificou limitações e potencialidades para a análise do squash. Limitações pela notória carência da produção científica deste jogo esportivo. Por isso que escolhemos investigar apenas o duelo 1x1 para podermos focar em uma analítica do esporte. No tocante às potencialidades, acreditamos que poderemos ampliar uma análise futura para o duelo $2 \times 2 \mathrm{com}$ mais estrutura e arcabouço teórico. Além disso, buscamos que os praticantes e profissionais envolvidos com o squash possam conhecer a teoria da ação motriz e o quanto a PM, criada pelo o Prof. Pierre Parlebas e investigada por diferentes pesquisadores do Brasil e do mundo favorece a ampliação do conhecimento, entendimento e aplicação do jogo que se é pedagogizado e/ou praticado.

Esperamos que este artigo suscite e provoque a produção de novos e profundos estudos sobre o squash sob a luz da praxiologia motriz por estudantes e profissionais da área da educação física. Com isso, estaremos avançando no estudo dos esportes para além da esfera técnica e tática, mas sim, com vistas a uma produção de linguagem oriunda de uma gramática esportiva, um segundo olhar para os sentidos e significados nas relações que estão presentes dentro de qualquer jogo esportivo.

\section{REFERÊNCIA}

COSTA, Marina Luisa de Lima Costa; SILVA, Mauro Amâncio da. O ensino da técnica de squash: uma abordagem metodológica. Do corpo: ciências e artes, Caxias do Sul, v. 1, n. 3, 2013. Disponível em: http://www.ucs.br/etc/revistas/index.php/docorpo/article/view/2912

GOMES-DA-SILVA. Pierre Normando; SOUSA-CRUZ, Rodrigo W; ARRUDA, Emerson P. S. Entre o lance a chance: lógica interna numa final do badminton. Motrivivência, v. $31, \mathrm{n}$. 58, p. 1-19, abril/julho, 2019. Disponível em:

https://periodicos.ufsc.br/index.php/motrivivencia/article/view/2175-8042.2019e56349

GONZÁLEZ, Fernando Jaime. Planejamento curricular na educação física escolar: diálogos com a praxiologia motriz. In: RIBAS, J. F. M (Org.). Praxiologia motriz na América Latina: aportes para a didática na educação física. Ijuí: Editora Unijuí, 2017.

GOMES-DA-SILVA. Pierre Normando; OLIVEIRA, Diego Moreira da Costa; FARIAS, George de Paiva; SOUSA-CRUZ, Rodrigo Wanderley; SOARES, Leys Eduardo dos Santos; RIBAS, João Francisco Magno. Estratégia motriz no handebol de areia: uma análise praxiológica. Revista Acción Motriz, n. 19, p. 59-70, 2017. Disponível em:

http://docplayer.com.br/74595741-Estrategia-motriz-en-el-balonmano-playa-un-analisispraxiologico-estrategia-motriz-no-handebol-de-areia-uma-analise-praxiologica.html 
LAGARDERA, Francisco; LAVEGA, Pere. Fundamentos da praxiologia motriz. In: RIBAS, João Francisco Magno. (Org.) Jogos e Esportes: fundamentos e reflexões da Praxiologia Motriz. Santa Maria: Editora da UFSM, 2008. p. 45-79.

LAVEGA, Pere. Classificação dos jogos, esportes e as práticas motrizes. In: RIBAS. J. F. M. (Org.) Jogos e Esportes: fundamentos e reflexões da Praxiologia Motriz. Santa Maria: Editora da UFSM, 2008. p. 81-103.

PARLEBAS, Pierre. Juegos, Deporte y Sociedad: Léxico de Praxiologia motriz. Barcelona: Paidotribo, 2001.

REDFERN, Karen; NETO, Nelson; RODRIGUES, Gilvandro. Regras mundiais do squash individual com edição em português. Tradução original por Nelson Neto e Karen Redfern, Adaptação para Regras 2010, Revisão e Formatação por Gilvandro Rodrigues, WFS (World Squash Federation), CBS (Confederação Brasileira de Squash), FSPB (Federação Squash Paraíba), 4 mar. 2018.

RIBAS, João Francisco Magno. Jogos e Esportes: fundamentos e aplicações da Praxiologia Motriz. Santa Maria- RS: Editora UFSM, 2008.

SOARES, Leys Eduardo dos Santos; GOMES-DA-SILVA. Pierre Normando; RIBAS, João Francisco Magno. Comunicação motriz nos jogos populares: uma análise praxiológica. Movimento, Porto Alegre, v. 18, n. 3, p.159-182. jul./set., 2012.

SOUSA-CRUZ, Rodrigo Wanderley, et al. Jogo tradicional e esportivo: para além de suas relações dicotômicas. In: GOMES-DA-SILVA. Pierre Normando CAMINHA, Iraquitan de Oliveira. Movimento humano: incursões na educação e na cultura. Curitiba: Appris, 2017.

SOUSA-CRUZ, Rodrigo Wanderley; GOMES-DA-SILVA. Pierre Normando; RIBAS, João Francisco Magno. Jogo tradicional-popular e aprendizagem: uma análise teórica das comunicações dos jogadores. Rev. bras. Estud. pedagog. (online), Brasília, v. 96, n. 244, p. 683-701, set./dez. 2015. Disponível em: https://www.scielo.br/scielo.php?pid=S2176$\underline{66812015000300683 \& \text { script }=\text { sci abstract\&tlng }=p t}$

SOUSA-CRUZ, Rodrigo Wanderley; FARIAS, George de Paiva; ANTERIO, Djavan; SOARES, Leys Eduardo Santos; OLIVEIRA, Danielle Menezes de; RIBAS, João Francisco Magno; GOMES-DA-SILVA, Pierre Normando. Interação e criação no jogo barra-bandeira: aprendizagem na perspectiva parlebasiana e winicottiana. Revista EFDeporte, Buenos Aires, v. 19, n. 201, febrero, 2015. Disponível em:

https://www.efdeportes.com/efd201/interacao-e-criacao-no-jogo-barra-bandeira.htm 